\title{
Projeto integrador e processo de (res)significação do ensino de literatura: experiência em um curso de administração integrado ao médio
}

Luciane Senna Ferreira ${ }^{1}$

\begin{abstract}
Resumo
A presente narrativa parte da experiência do projeto desenvolvido com estudantes do terceiro ano do curso Técnico em Administração Integrado ao Ensino Médio, no primeiro e segundo trimestre letivo/2019, no Instituto Federal do Rio Grande do Sul/Campus Osório/RS, envolvendo as disciplinas de Língua Portuguesa e Literatura, Artes e Marketing. Privilegiou-se o texto literário como partida para um conjunto de atividades que contemplaram habilidades de leitura, produção oral e escrita, criação artística e divulgação da produção final à comunidade interna e externa ao campus. Para a construção do projeto, adotaram-se as perspectivas de Filipouski \& Marchi (2009) sobre o trabalho com o texto literário pautado por ações de construção de sentidos, e de Simões (2012), de que leitura é interação dialógica e produções textuais são atividades sociointerativas. Os estudos de Schmidt (1995; 2008) e Dalcastagnè (2005; 2012), sobre o cânone literário como espaço que consagra uma literatura sem marcas sociais da diferença, favorecendo o silenciamento das vozes de negros e mulheres, e o apagamento das obras de autoria feminina, orientaram a escolha do romance centro do projeto, Úrsula, de Maria Firmina dos Reis. Os resultados da proposta contribuíram para pensar numa experiência integradora e num processo de (res) significação do ensino de literatura na Educação Básica.
\end{abstract}

Palavras-chave: Literatura. Ensino. Projeto integrado.

\section{Resumen}

Esta narrativa parte de la experiencia del proyecto desarrollado con estudiantes de tercer año de la Enseñanza Secundaria Integrada de Administración, en el primer y segundo trimestre escolar/2019, en el Instituto Federal de Rio Grande do Sul/Campus Osorio/RS, que involucra las disciplinas de Lengua Portuguesa y literatura, Artes y Marketing. El texto literario fue privilegiado como punto de partida para un conjunto de actividades que incluían habilidades de lectura, producción oral y escrita, creación artistica y difusión de la producción final a la comunidad interna y externa del campus. Para la construcción del proyecto, adoptamos las perspectivas de Filipouski y Marchi (2009) sobre el trabajo con el texto literario guiado por acciones de construcción de significado, y los estudios de Simões (2012), en el cual la lectura es interacción dialógica y producciones textuales son actividades socio-interactivas. Los estudios de Schmidt (1995; 2008) y Dalcastagnè (2005; 2012), sobre el canon literario como un espacio que consagra una literatura sin signos sociales de diferencia, favoreciendo el silenciamiento de las voces de negros y mujeres, y el borrado de obras de autoría femenina, guiaron la elección de la novela centro del proyecto, Úrsula, de Maria Firmina dos Reis. Los resultados de la propuesta contribuyeron a pensar en una experiencia integradora y un proceso de (re)significado de la enseñanza de literatura.

Palabras-clave: Literatura. Enseñanza. Proyecto integrado.

\footnotetext{
${ }^{1}$ Mestra em História da Literatura pela Universidade Federal do Rio Grande (FURG). Docente do Instituto Federal do Rio Grande do Sul (IFRS), Campus Osório. Atua no Ensino Médio Técnico Integrado e no curso de Licenciatura em Letras Português/Inglês.
} 


\section{Introdução}

Embora se tenha práticas pedagógicas potencialmente significativas no campo do ensino da literatura presentes em sites acadêmicos, revistas especializadas, livros e outros, e que estão presentes em escolas com boas estruturas, acesso à internet e biblioteca, docentes com ampla formação e preparo, ainda é um desafio o trabalho com o texto literário na sala de aula. Maior se torna ele em contexto de ensino médio técnico, quando as disciplinas da formação geral e técnicas devem dialogar com a finalidade de promover um processo de ensino-aprendizagem integral ao jovem estudante. Somado a isso, encontra-se a problemática do trabalho com a literatura relacionada aos próprios equívocos da forma de ensino, que ocorrem sempre que são privilegiados, na sala de aula, categorização de gêneros literários, periodização e características, vida de autores, história da literatura, léxicos e estudos gramaticais isolados, em detrimento daquilo que deveria estar no centro do processo educacional: a leitura das obras e a produção de sentidos. Somente a partir da obra e por ela é que cabe o trabalho com a história da literatura e seu contexto de produção; tradição e rupturas; valores estéticos; intertextualidade; teoria literária; língua como objeto da cultura, alcançando, assim, uma prática significativa e portadora de sentidos provocada pela leitura, que se complementará na produção textual escrita e/ou oral.

Não menos relevante é a função humanizadora da literatura como alargamento dos horizontes e aprofundamento das formas de ver o mundo e si mesmo que "esbarra no apagamento das diferenças ou no elitismo de algumas visões do cânone" (BARBOSA, 2017, p.133). De acordo com Rita Schmidt (2008), em certos contextos institucionais no campo das Letras, há uma extrema valorização de discursos voltados à preservação e à continuidade de saberes constituídos na perspectiva da literatura canônica, que buscam uma homogeneização da literatura nacional, consagrando uma definição que exclui as marcas sociais da diferença. Isso favorece, sobretudo, a um silenciamento de vozes indígenas, de mulheres, de negros, da comunidade LGBTI+, falsificando uma cultura livre de tensões e conflitos.

Dentro deste mesmo pensamento, Regina Dalcastagnè vem desenvolvendo um potente trabalho de pesquisa na Universidade de Brasília (UnB) sobre autores e romances publicados pelas grandes editoras, e as profissões e os papeis sociais das personagens presentes nestas narrativas. Os estudos da pesquisadora apontam que há uma repetição do 
mesmo, com autores e personagens brancos, homens, classe média, heterossexuais, sem deficiências, moradores dos grandes centros urbanos. Nessa perspectiva, fica evidente que as escritoras mulheres são minoria publicada no Brasil; que o cânone literário é composto majoritariamente por escritores homens e brancos; e que na história da literatura brasileira há o apagamento das obras de autoria feminina e, sobretudo, de autoria feminina negra.

Essa homogeneização e monopólio também estão presentes no interior das narrativas. Segundo Dalcastagnè (2005), o que se indaga hoje não é o fato de que a literatura fornece determinadas representações da realidade, mas sim que essas representações não são representativas do conjunto das perspectivas sociais. 0 problema da representatividade, portanto, não se resume apenas à honestidade na busca pelo olhar do outro ou ao respeito por suas peculiaridades. Está em questão a diversidade de percepções do mundo, que depende do acesso à voz, tanto na produção quanto na leitura, das minorias silenciadas, e que não é suprida pela boa vontade daqueles que monopolizam os lugares de fala.

Portanto, não basta, nas narrativas literárias, que o outro fale por determinados grupos sociais mesmo tendo respeito pelas suas particularidades, pois a sua percepção de mundo sobre estes grupos será sempre restrita. Para autora, o que de fato está em questão é a representatividade através do local de fala, que só será possível dando a esses sujeitos 0 acesso à voz por meio da democratização da literatura, tanto da leitura quanto da produção, permitindo, assim, "no campo literário brasileiro, uma pluralidade de perspectivas sociais" (DALCASTAGNÈ, 2005, p. 18), pois, de acordo com o posicionamento diferente que os sujeitos ocupam na sociedade, as experiências, as histórias, os anseios e os desejos são também diferentes.

Assim, mulheres e homens, trabalhadores e patrões, velhos e moços, negros e brancos, portadores ou não de deficiências, moradores do campo e da cidade, homossexuais e heterossexuais, umbandistas e católicos vão ver e expressar 0 mundo de diferentes maneiras. Mesmo que outros possam ser sensíveis a seus problemas e solidários, nunca viverão as mesmas experiências de vida e, portanto, verão o mundo social a partir de uma perspectiva diferente. Por mais solidário que seja às mulheres, um homem não vai vivenciar o temor permanente da agressão sexual, assim como um branco não tem acesso à experiência da discriminação racial ou apenas um cadeirante sente cotidianamente as barreiras fisicas que dificultam ou impedem seu trânsito pelas cidades. (DALCASTAGNĖ, 2005, p. 19) 
Ao trabalhar a literatura contemplando uma pluralidade de vozes, inserindo a de autoria feminina, sobretudo de mulheres negras, na sala de aula, será possível abordar muitas temáticas e aspectos narrativos diferentes da produção de autoria masculina branca.

Quase sempre as mulheres são representadas pelos escritores em temas como sedução, beleza, fragilidade, meiguice, raras vezes é mencionado ou explorado o que elas pensam ou desejam. Campos (2008) pontua que se percebe, ainda, no caso das personagens de mulheres negras, que elas não aparecem como musas, heroínas ou românticas.

Para as mulheres, tanto negras ou brancas, a literatura foi por muito tempo espaço de exclusão e de negação da sua participação. Seus discursos foram silenciados e, portanto, não tiveram a mesma inclusão no cânone literária em relação aos homens brancos. A eles foi reservado o domínio sobre as letras, a elas a invisibilidade. Em geral,

“[...] a negação da legitimidade cultural da mulher, como sujeito do discurso exercendo funções de significação e representação foi, no contexto das literaturas, uma realidade que perdurou até, mais ou menos, a década de 1970 (NAVARRO; SCHMIDT, 2007, p. 86).

Buscando a sua autorrepresentação, as mulheres expressam seus próprios desejos poéticos, suas dores, suas lutas, suas histórias, seus anseios e suas memórias no fazer literário. Vão se apresentando e se autorrepresentando por suas próprias mãos e rompem com os estereótipos que lhe eram e são atribuídos na história e na tradição da literatura brasileira. Através das mulheres, novas imagens passam a existir, uma pluralidade poética construída por vozes como de Maria Firmina dos Reis, Carolina Maria de Jesus e Conceição Evaristo.

Um ensino de literatura direcionado à prática plural, na qual privilegia estas vozes, propiciará aos jovens leitores a chance de construir outro tipo de relação com o texto, novos sentidos e significados, inclusive, promoverá a possibilidade de democratizar a própria escrita literária ao incentivar a construção autoral de estudantes tão diversos que estão presentes nas salas de aulas: brancos, negros, mulheres, indígenas, deficientes.

Uma prática amparada por esta visão é capaz de ampliar, de fato, o alargamento dos horizontes e aprofundamento das formas de ver o mundo e a si mesmo, pois conhecerão outras vozes literárias para além daquelas que são culturalmente legitimadas pelo cânone literário tradicional. 
As diferenças da organização social em gênero, classe, raça/etnia, resultam, sempre, em diferenças literárias, a escrita feminina negra, por exemplo, é permeada desses elementos. A definição de Conceição Evaristo dado ao termo cunhado e nomeado por ela, escrevivência², deixa tais traços bem claros:

\begin{abstract}
A escrevivência seria escrever a escrita dessa vivência de mulher negra na sociedade brasileira. Eu acho muito difícil a subjetividade de qualquer escritor ou escritora não contaminar a sua escrita. De certa forma, todos fazem uma escrevivência, a partir da escolha temática, do vocabulário que se usa, do enredo a partir de suas vivências e opções. A minha escrevivência e a escrevivência de autoria de mulheres negras se dá contaminada pela nossa condição de mulher negra na sociedade brasileira. Toda minha escrita é contaminada por essa condição. É isso que formata e sustenta o que estou chamando de escrevivência. (EVARISTO, 2005, p. 36)
\end{abstract}

Diante dessa conjuntura, surgem novas questões desafiadoras aos educadores de Ensino Médio, principalmente, em contexto técnico-tecnológico, que anseiam não só trabalhar a literatura, mas trabalhá-la em projeto com outras disciplinas do currículo técnico. Pois não cabe apenas pensar como levar estudantes à leitura literária, quais procedimentos metodológicos e didáticos a serem adotados e quais atividades serão desenvolvidas, mas, fundamentalmente, quais obras e qual abordagem de leitura se deve adotar.

Assim sendo, o presente trabalho pretende narrar uma experiência de ensino que buscou responder às questões desafiadoras do ensino da literatura quanto à obra a ser trabalhada e abordagem direcionada à leitura através de um trabalho com a produção do gênero seminário e resenha crítica, leitura, elaboração de uma revista e estratégias de marketing para sua divulgação, desenvolvidas pelos professores de Língua Portuguesa e Literatura, Artes e Marketing do Instituto Federal do Rio Grande do Sul - Campus Osório junto a uma turma de terceiro ano do curso Técnico em Administração Integrado ao Ensino Médio deste campus, durante o primeiro e segundo trimestre letivo de 2019, tendo como centralidade a obra Úrsula da autora Maria Firmina dos Reis. As atividades propostas se dividiram em várias etapas com o objetivo de superar práticas tradicionais de ensino que se orientam por aspectos estruturais e que são isoladas, buscando, desta maneira, outras formas

\footnotetext{
${ }^{2}$ Sobre o termo escrevivência, Evaristo afirma não ser um conceito buscado por ela, enquanto pesquisadora, mas parte de sua própria experiência como mulher negra, bem como da experiência dos seus irmãos negros. Acessar Ocupação Conceição Evaristo - escrevivência - Itaú Cultural. Disponível em http//www. itaucultural.org/ocupacao/conceicao-evaristo/escrevivencia/. Acesso 10 jun. 2019.
} 
de trabalho que sejam integradas e significativas aos estudantes, privilegiando, assim, a interdisciplinaridade.

\section{Processo de planejamento: o projeto e as escolhas orientadas à leitura e à produção textual}

Foi pensado um projeto que pudesse se aproximar o máximo possível das demandas desafiadoras postas a partir das inquietações a respeito do trabalho com texto literário em sala de aula voltado para construção de sentidos e interação dialógica; das problematizações elencadas pelos discentes do curso de Licenciatura em Letras do Campus Osório, sobre cânone literário e a ausência de produções por mulheres e negros no ensino da literatura; do potente trabalho das Ações Afirmativas desenvolvido pelo Núcleo de Estudos e Pesquisas em Gênero e Sexualidade (NEPGS) e Núcleo de Estudos Afro-brasileiros e Indígenas (NEABI); e das diretrizes do ensino integrado presente no Projeto Pedagógico do Curso Técnico em Administração Integrado ao Ensino Médio³, em que os docentes elegeram a mobilização para interdisciplinaridade como eixo e objetivo a perseguir.

O gênero romance foi escolhido para a realização do projeto integrador, pois é um gênero que contribui e promove o acesso à leitura e à melhora do letramento, abrindo espaços para se trabalhar outros gêneros na sala de aula a partir da perspectiva de Bakhtin (2003) sobre a classificação deles em primários (simples) e secundários (complexos), o primeiro constituindo-se da comunicação verbal cotidiana (bilhetes, cartas pessoais, diálogos, etc.) e o segundo (romance, teatro, discurso científico, discurso jornalístico, etc.) das circunstâncias de comunicação culturais mais complexas, principalmente escritas, absorvendo os gêneros primários. Ainda, pelo romance, o texto é formado a partir de uma complexidade de ações, o que causa efeitos de sentido no leitor em grande escala.

Sendo o romance uma narrativa que procura transportar para a ficção a experiência humana, apresenta-se como um gênero privilegiado para o trabalho com a literatura em sala de aula. De acordo com Watt, o gênero romance:

\footnotetext{
3 Para acessar Projeto Pedagógico do Curso Técnico em Administração Integrado ao Ensino Médio https://osorio.ifrs.edu.br/site/midias/arquivos/201710684831636ppc administracao - emi.pdf
} 
[...] constitui um relato completo e autêntico da experiência humana e, portanto, tem a obrigação de fornecer ao leitor detalhes da história como a individualidade dos agentes envolvidos, os particulares das épocas e locais de suas ações - detalhes que são apresentados através de um emprego da linguagem muito mais referencial do que é comum em outras formas literárias (WATT, 1990, p. 31).

Nessa perspectiva, o romance Úrsula apresenta discussões acerca da sociedade em diversos âmbitos e, por meio da narrativa de vozes negras que foram e são silenciadas, é possível ver o mundo de forma diferenciada e, consequentemente, mudar posturas diante da sociedade. Assim, estudar o gênero romance, na obra de Firmina, que trata da situação da escravidão brasileira, constitui-se numa oportunidade significativa, pois se percebe, na obra, uma grande preocupação por parte da autora em discutir questões como a desigualdade, a injustiça, a violência, a classe, a cor, a liberdade e o aprisionamento.

Estudar a obra, em sala de aula, permite que os alunos compreendam a situação da escravidão, o descaso da sociedade, a miséria, os maus-tratos, provocando reflexões sobre o tema e percepções sobre o passado e o presente, e que, principalmente, possam tomar postura crítica diante do assunto. A importância da leitura dessa obra está em sua contribuição, naquilo que diz respeito à discussão do tema da escravidão e seus impactos na população negra, conflitos e tensões que atravessaram séculos, e que persistem até os dias atuais, bem como o que ela representa dentro do estudo da literatura ao trazer para o debate a autoria feminina negra.

Maria Firmina dos Reis, maranhense, (1825-1917) é a primeira romancista brasileira, autora também do primeiro romance abolicionista do país: Úrsula (1859). Além de mulher, era negra e filha "bastarda", fatos que contribuiriam para a marginalização de qualquer indivíduo na época e certamente contribuíram para a ausência da autora em nossa historiografia literária (CORREIA, 2013) e, consequentemente, o estudo de sua obra no universo educacional.

É nesse contexto que se entende a importância dessa obra na formação de leitores, pois é um livro com grande capital cultural para o país. Esquecido por longo tempo, hoje, é feito o trabalho de resgate e análise de sua obra no meio acadêmico, o que leva a mais um ponto para escolha desta obra. Trabalhar este romance também é uma forma de preparar os alunos desta turma para o processo seletivo de ingresso na graduação da Universidade Federal do Rio Grande do Sul (UFRGS), pois Úrsula é uma das leituras obrigatórias para o vestibular de 2019 e 2020, desta instituição, em que muitos estudantes do campus Osório participam. 
Selecionado o romance foco do projeto, partiu-se para o planejamento da produção textual. Quanto ao texto oral, conteúdo previsto no componente curricular da disciplina de Língua Portuguesa e Literatura III, optou-se pelo seminário em grupos sobre a obra Úrsular a partir do pressuposto de que:

\begin{abstract}
A necessidade de o aluno aprender formas diferentes de falar, se comparadas às formas utilizadas na conversa cotidiana, no meio social que já conhece não determina que ele coloque o como dizer à frente daquilo que quer dizer e do fato que está dizendo algo a alguém [...] introduzir o estudante nos modos de falar mais formais e introduzi-lo em mundos onde tais falas ganham sentido e dos quais ele pode participar. (SIMÕES, 2001, p.50)
\end{abstract}

Diante deste gênero, amplia-se a noção de interação, não sendo apenas através da leitura, mas também da produção de textos orais, no qual o aluno busca um ponto de vista próprio e a construção de uma forma de expressá-lo. Caracteriza-se como um momento de desenvolvimento da competência comunicativa do sujeito, o que seria a capacidade de conhecer e utilizar a língua a partir das experiências sociais, das necessidades e objetivos. 0 seminário não é mais um simples momento de socialização de textos, mas sim de construção de sentidos que se concretizam na fala.

Como produção textual escrita, selecionou-se resenha crítica da obra foco do projeto, gênero textual também previsto no componente curricular da disciplina de Língua Portuguesa e Literatura III do ensino médio. Este gênero é capaz de proporcionar aos estudantes um conhecimento maior em relação às capacidades de linguagem empregadas na produção de textos, pois vai mobilizar as operações discursivas que dizem respeito à planificação textual, à organização sequencial e sua articulação, à escolha e elaboração dos conteúdos. $\mathrm{Na}$ resenha, a apresentação do texto fonte se dá pela predominância de sequências descritivas, de acordo com (MOTTA-ROTH, 1996), que orientam o leitor quanto à organização e tratamento dos conteúdos nesse texto, seguindo a ordem de ocorrência deles no texto fonte. O gênero resenha também explora o aspecto do conteúdo temático a ser mobilizado na produção, pois necessita que o estudante leia o livro, interprete-o, sumarize-o e posicionese. Nesse caso, ao se posicionar a respeito da obra, ele assume e defende uma opinião e tem que expor argumentos bem fundamentados capazes de convencer seus leitores a respeito do posicionamento assumido no texto. 
É relevante ter no horizonte do trabalho com o texto, que toda a produção deve ter sentido para àquele que a produz e isso só ocorre, de fato, se houver uma produção efetiva, isto é, que ao final da organização e planejamento das atividades, elas sejam lidas, na escola ou fora dela, efetivando, assim, a ação na linguagem:

[...] ainda que muitas vezes estejam limitadas ao contexto concreto da escola - a leitura literária em classe ou em casa - deve ter sempre uma finalidade reconhecível e compatível com o gênero do texto lido [...] somente assim torna-se significativa, pois retoma as funções sociais nas quais um texto encontra sua função. (FILIPOUSKI; MARCHI, 2009, p.11)

Ainda, as autoras apontam que:

Qualquer produção sobre algo lido, fora do contexto escolar, acaba sempre tendo um destinatário concreto e um objetivo definido. Ao ser escolarizada, a produção textual também precisa assegurar um espaço de manifestação significativa, sinalizando que a produção oral ou escrita a partir da leitura é para outros leitores (em potencial ou concreto), não um artifício forjado para prestar contas ao professor (FILIPOUSKI \& MARCHI, 2009, p.21).

No projeto, realizamos uma produção textual com propósito claro e definido de que ela seria para outros leitores concretos além do professor, já que no final do conjunto das atividades propostas os alunos tiveram suas resenhas publicadas em uma revista on-line que eles próprios construíram, com o objetivo de que suas produções fossem socializadas com a comunidade interna e externa ao campus ${ }^{4}$. Articulada a esta dimensão, tornando a produção escrita em uma manifestação ainda mais real e significativa, a revista com as resenhas da obra Úrsula tinha também o propósito de divulgar a autora, que durante tanto tempo ficou esquecida; trazer a literatura feminina de autoria negra para o cotidiano escolar, dialogando assim com demandas do NEPGS5; fazer alusão ao dia 25 de julho, Dia Internacional da Mulher Negra Latino-Americana e Caribenha e Dia Nacional de Tereza de Benguela, indo ao encontro das temáticas do $\mathrm{NEABI}^{6}$; proporcionar aos alunos das outras turmas da escola uma leitura que possa os auxiliar no processo seletivo de ingresso na UFRGS; e levar ao ambiente escolar um meio acessível para divulgação e leitura de produções dos alunos do ensino médio do Campus Osório, já que não há custo de publicação impressa.

\footnotetext{
4 Endereço da revista: https://view.joomag.com/resenha-da-301-adm-resenha-da-301adm/0347770001567600378? short.

5 NEPGS - Núcleo de Estudos e Pesquisas em Gênero e Sexualidade.

${ }^{6} \mathrm{NEABI}$ - Núcleo de Estudos Afro-Brasileiros e Indígenas.
}

LínguaTec, Instituto Federal de Educação, Ciência e Tecnologia do Rio Grande do Sul, Bento Gonçalves V. 4, n. 2, p. 229-245, nov. 2019. 
Concluída a etapa de planejamento, escolhas e organização do projeto, procedeu-se ao seu desenvolvimento. Todas as atividades, objetivos, modo de desenvolvimento, etapas e critérios de avaliação foram compartilhados previamente com os estudantes, de forma que eles tivessem conhecimento de todo o processo e, assim, participassem dele de forma efetiva e colaborativa.

\section{Desenvolvendo o projeto: a prática}

O projeto foi desenvolvido através de um conjunto de atividades propostas de múltiplas tarefas interligadas que buscaram culminar no estabelecimento de formas de diálogo por meio dos textos escritos e falados produzidos pelos alunos, procurando ir ao encontro das colocações de Simões (2012) ao discutir a importância das propostas concretas de ensino de literatura na escola.

As atividades de leitura, produção oral e escrita foram desenvolvidas na disciplina de Língua Portuguesa e Literatura, no primeiro trimestre letivo; a construção da revista on-line, produzida no segundo trimestre, contou com as três disciplinas, Artes, Marketing e Língua Portuguesa e Literatura. Ainda, ocorreu a segunda reescrita das resenhas a partir das correções e sugestões dadas pela professora de língua; e estratégia de divulgação da revista ficou sob a responsabilidade da disciplina de Marketing, também no segundo trimestre.

Na leitura do texto literário, articuladas às perspectivas de Simões e Filipouski \& Marchi (2009) adotou-se as estratégias de Rildo Cosson (2006) que se constituem em uma sequência básica e uma sequência expandida de letramento literário, partindo do texto. 0 primeiro passo foi a motivação que consistiu "exatamente em preparar o aluno para entrar no texto" (COSSON, 2016, p. 54) a partir da exibição de um vídeo do poema "O navio negreiro", de Castro Alves e de questões orais referentes às imagens presentes no poema, provocando a discussão acerca do conteúdo temático presente no texto, a escravidão.

A introdução foi o segundo passo, momento em que autora e obra foram apresentadas à turma. Neste passo também se orientou as possibilidades de acesso ao livro, fornecendo sites onde a obra poderia ser lida, indicação de editoras para sua aquisição e da biblioteca da escola que conta com alguns exemplares, ainda, solicitou-se uma pesquisa mais aprofundada sobre a autora. 
O terceiro passo, então, foi a leitura, que precisou de orientação, pois tinha uma direção, finalidade e um objetivo a cumprir. Por se tratar de texto extenso, o teórico orienta que a leitura seja feita fora da escola, prática que se adotou. Durante o período estabelecido para atividade de leitura, os alunos iam apresentando os resultados parciais a partir de questionamentos com a turma sobre o andamento da história, número de capítulos lidos, dificuldades encontradas em relação à linguagem, quais sentidos estavam depreendendo da obra e outros aspectos.

O quarto passo da sequência básica é a interpretação, Cosson (2006) propõe que em um cenário de letramento literário, devemos pensá-la em dois momentos: interior e exterior. O primeiro é individual, é aquele que acompanha a obra palavra por palavra, que decifra capítulo por capítulo, até chegar à apreensão global da obra, que se realiza logo após o término da leitura. 0 momento externo é a concretização do ato de construção de sentido em uma determinada comunidade de leitores, em nossa experiência, a comunidade leitura foi a própria turma em sala de aula.

Na sequência expandida, a motivação, a introdução e a leitura continuam como primeiros passos. A interpretação passa a ser dividida em primeira e segunda interpretação. $A$ primeira é a apreensão global da obra: o objetivo foi levar aluno a traduzir a impressão geral do título e o impacto que ele teve sobre sua sensibilidade de leitor. Depois da primeira interpretação, o aluno foi levado ao entendimento do contexto da obra, que compreende 0 aprofundamento da leitura por meio dos contextos que ela traz, e divide-se em: contextualização teórica, histórica, estilística, poética, crítica, presentificadora e temática. A segunda interpretação para Cosson (2006) tem por objetivo a leitura aprofundada de um de seus aspectos, e pode ter como foco um tema, um traço estilístico, uma personagem. 0 último passo, nesse projeto, foi adaptado para seminário orientado, adotou-se uma interpretação mais ampla, igualmente aprofundada, porém contemplando vários aspectos da obra e não apenas um.

Para a produção do gênero seminário, a turma foi dividida em sete grupos, contendo cada um quatro alunos, que em um trabalho sequencial responderam às questões norteadoras disponibilizadas pela professora acerca da obra: a) como é abordada a presença da mulher e sua condição feminina; b) papéis sociais que as mulheres desempenham; c) a representação da condição dos negros (homens e mulheres); d) a construção das personagens masculinas 
quanto a seus traços característicos comparados a outras personagens dos períodos literários anteriores; e) valores atribuídos aos negros comparados aos brancos e a outras obras produzidas até o século XIX (romantismo, realismo, barroco); f) contexto de produção (quem escreve, quando, sociedade no momento da produção) para construção do romance Úrsula; e g) elementos da narrativa que a estruturam: narrador, tempo, espaço, enredo, personagens e linguagem empregada.

Para a realização de cada execução das etapas de construção do seminário, os alunos tiveram momentos coletivos de orientação durante as aulas, assim como, foram disponibilizados momentos particulares, caso os grupos necessitassem.

Após o término do seminário, que ocorreu em cinco encontros de $50 \mathrm{~min}$. cada, os alunos partiram para as produções da resenha crítica, que podem ser visualizadas no link já mencionado, neste texto, sobre a revista produzida pelos estudantes. Alguns estudantes sugeriram a possibilidade de produzirem o texto em dupla, pois trabalharam em grupo no seminário e suas temáticas iriam orientar o foco da resenha, outros optaram por produção individual, quanto a este aspecto, tiveram a liberdade de escolha.

Os discentes, neste momento, já estavam preparados para produzirem a resenha, efetivando a ação na linguagem, a partir do trabalho da leitura e do seminário, no qual, por meio dos temas norteadores, foi desenvolvida uma leitura aprofundada da obra, reflexões, debates e construção de sentidos, bem como porque, desde o começo do trimestre, as aulas de Língua Portuguesa e Literatura estavam explorando, concomitantes às demais atividades, o gênero resenha crítica.

Estabeleceu-se um prazo de dez dias para entrega da atividade, entre esse período, procedeu-se a uma revisão sobre o gênero resenha e disponibilizou-se espaços para sanar dúvidas que ainda podiam existir. Após a entrega da produção escrita, pelos alunos, elas foram corrigidas e devolvidas para a reescrita.

A avaliação foi contínua durante todo o processo das atividades, entretanto, alguns critérios foram estabelecidos previamente com os alunos. Quanto à leitura: cumprir o prazo; discutir os resultados parciais da leitura em sala de aula; apresentar a pesquisa sobre a autora. Em relação à produção do gênero seminário, momento em que demonstraram a apropriação da obra lida: adequação ao gênero; participação de todos do grupo, distribuindo bem o tempo entre cada um; abordagem adequada da obra conforme o tema; clareza, coerência, ideias 
encadeadas, introdução, desenvolvimento e conclusão; bom uso dos recursos utilizados para apresentar o seminário; trazer leituras pessoais e interpretativas acerca obra. Para produção escrita: adequações ao gênero; questões de pontuação; estrutura de frases e parágrafos; vocabulário e ortografia; o posicionamento e argumentação; o desenvolvimento do texto de uma forma clara para o leitor; a criatividade. Estes foram todos os aspectos analisados na avaliação da atividade.

Ao final da avaliação do seminário, produziu-se um parecer no qual continha observações para cada critério avaliativo e um global, pontuando os aspectos positivos, bem como aqueles que precisavam melhorar. Para as resenhas, algumas correções ocorreram no próprio texto e outras no parecer orientando para reescrita. $O$ objetivo de ambas as avaliações não era corrigir os alunos/grupos ou apontar erros, mas sim propor possibilidades para que eles pudessem desenvolver cada vez mais as habilidades com competência.

Com a finalização deste conjunto de atividades, as notas do trimestre foram fechadas e não houve alunos abaixo da média, todos corresponderam bem às propostas, demonstraram interesse, participação efetiva e colaboração em grupo.

No segundo trimestre, então, desenvolveu-se a proposta da criação da revista, na qual as produções textuais do gênero resenha seriam publicadas e divulgadas à comunidade interna e externa ao campus. Nesta etapa, as três disciplinas envolvidas no projeto atuaram concomitantemente. 0 primeiro passo foi trabalhar com a turma o conceito de revista, modelos, propósito, receptores, objetivos, estrutura, identidade visual, criatividade, o meio de circulação e formas de divulgação. A disciplina de Artes explorou os aspectos indenitários da revista, criatividade, design e espacialidade; Marketing o meio de circulação, público alvo e formas de divulgação; Língua Portuguesa e Literatura a estrutura, editorial, edição. Embora cada disciplina tenha ficado responsável por determinados aspectos, o desenvolvimento deste processo não resultou em um trabalho isolado, pois o diálogo foi constante entre todos os participantes, alunos e professores, em todas as etapas.

Para construção da revista, foi distribuído à turma um conjunto de tarefas para as quais deveriam selecionar os responsáveis: a) Marketing Editorial: preparar estratégias de lançamento; b) Designer: a arte da revista, definindo os aspectos visuais da publicação, desde o tamanho e o tipo das letras até a disposição dos textos, ilustrações, fotografias e outras imagens; c) Meio digital de publicação: parte tecnológica, que consistia definir o local de 
publicação da revista (site, blog ou Facebook), pois já havia sido estabelecido que a circulação fosse on-line devido ao alcance e facilidade proporcionado pela internet, bem como pela consciência ambiental do uso de papel; d) Edição: indicar mudanças necessárias nos textos originais entregues pelos autores, visando à melhoria da sua qualidade ou adequação a determinado segmento de público; e) Tratamento de imagens: corrigir fotografias, como a luminosidade, o brilho, a cor e imperfeições nas imagens; f) Revisão final: eliminar desvios de informação e/ou de grafia.

Os alunos dividiram-se em grupos responsáveis pelas tarefas a partir das afinidades e interesses que tinham nelas. Ainda, foi trabalhado elementos, junto à turma, tais como: título da revista; corpo editorial; sumário; publicação em volume; editorial. E elementos do design: layout; grid; forma; tipografia; cor; imagem. Simultâneo a isso, ocorreu a segunda reescrita da resenha a partir da última correção que a professora de línguas havia feito e orientações de formatação para a publicação na revista.

A construção da revista foi o maior desafio do projeto, pois envolvia ativamente todo o grupo, 28 alunos, exigindo um trabalho coletivo no qual o diálogo e as trocas de informações eram fundamentais para se alcançar os objetivos propostos. Algumas dificuldades foram encontradas ao longo desta etapa, principalmente, sobre o ritmo de cada grupo, pois todas as tarefas estavam interligadas, como por exemplo, o tratamento de imagens que dependia do trabalho dos designers, e o atraso de um grupo interferia diretamente nos demais que dele dependiam para dar seguimento a suas tarefas. Diversas vezes os professores tiveram que intervir para mediar esta situação, estabelecendo prazos para que apresentassem os resultados parciais do que tinham desenvolvido até o momento.

A data da finalização da revista teve que ser adiada por duas vezes, o que causou atraso na sua divulgação, pois ela só poderia ir para circulação após ter passado pela aprovação final dos três docentes.

O prazo último de envio da revista aos docentes era dia 29 de agosto, a hospedagem no site dia 05 de setembro e o marketing editorial começaria no outro dia, com as seguintes estratégias: folders com QQR CODE que direcionasse diretamente à revista, sendo divulgados nos murais da escola e encaminhados por e-mail à comunidade da instituição com o link das redes sociais (Twitter e Instagram); auxílio do setor de comunicação para divulgação, tendo 
em vista todas as redes sociais do campus, abrangendo, assim, mais alunos e comunidade externa; visita nas salas de aulas de todas as turmas do diurno para divulgação da revista.

Todavia, o envio da revista ocorreu apenas no dia 04 de setembro, a correção finalizada no dia 11 e a hospedagem no site dia 12, o que alterou todo o cronograma e planejamento de estratégias de lançamento, pois o trimestre encerrou e esta etapa não pode ser cumprida dentro deste período, ficando para ser desenvolvida até o final deste mês de setembro.

Entre os critérios avaliativos, previamente informados à turma, estava o cumprimento do prazo e o marketing editorial. Para o primeiro houve desconto de nota e para o segundo não ocorreu pontuação. Entretanto, em todos os demais critérios obtiveram a nota máxima, totalizando 9,0 pontos.

Com esta última atividade, completa-se o ciclo das múltiplas tarefas interligadas propostas pelo projeto, que teve duração de dois trimestres, no qual foram trabalhadas diversas habilidades com a turma a partir de uma obra literária foco.

\section{Considerações finais}

Na narrativa de ensino aqui apresentada, mais que um aprendizado literário, houve uma profunda vivência de interação dialógica. O projeto ao contrário de “disseminar determinado valor literário, segundo critérios fixos e preestabelecidos, sem questionamentos, como se fossem categorias absolutas" (Schmidt, 2008, p.55), preferiu outro caminho, lançar luz à voz da escritora negra Maria Firmina dos Reis, que por muito tempo foi esquecida, suscitando, ao mesmo tempo, a reflexão crítica em relação à violência de gênero e raça.

Os alunos foram desafiados a todo o momento a superarem limitações e dificuldades e conseguiram dar respostas potentes a elas. Superaram a barreira da leitura de um texto longo e que exige uma prática silenciosa e isolada, muito distinta do que estão acostumados diante da frenética rapidez das redes sociais; enfrentaram discussões duras como racismo, escravidão, machismo, invisibilidade feminina, desconstruindo conceitos e os reconstruindo; ultrapassaram a ideia de que produzir textos e reescrevê-los é uma ação sem sentido com propósito único de cumprir uma exigência para obter aprovação; e buscaram formas e saídas de lidarem com os obstáculos que um trabalho em grupo muitas vezes faz emergir. Apesar da turma ter apresentado alguns problemas na última etapa, isso não comprometeu a trajetória 
do processo de aprendizagem durante o desenvolvimento do projeto e nem os resultados alcançados com a leitura, produções textuais e produto final, a revista.

Da experiência desse projeto, depreende-se que é necessário um olhar mais atento e reflexivo sobre o ensino da literatura em sala de aula, assim como, tratando-se de ensino e aprendizagem, é possível criarmos novas associações e novas metodologias e planejamentos curriculares integrados, de modo a fazer com que os alunos percebam que uma obra literária não apenas restringe-se ao texto escrito e à leitura, mas que se alarga amplamente em um tempo e espaço muito maior do que o apresentado por palavras.

Por fim, compreende-se que há formas de superar práticas isoladas de ensino por meio da interdisciplinaridade, passando de uma concepção de fragmentação das disciplinas para uma concepção de unidade, bem como contribuir para (res) significação do ensino de literatura na escola pública de ensino técnico do Brasil.

\section{Referências}

BAKHTIN, M. Estética da criação verbal. 4. ed. Trad. Paulo Bezerra. São Paulo: Martins Fontes, 2003.

BARBOSA, Daniela A. (Res) significando o ensino de literatura: uma experiência de círculo de leitura e leitura subjetiva com alunos de ensino médio. In. Anais do VIII Seminário dos Alunos dos Programas de Pós-Graduação do Instituto de Letras da UFF - Estudos Literários, $\mathrm{n}^{0} 1$. Niterói, RJ 2017, p. 132-148. Disponível em: file://C:/Users/Cliente/Desktop/para\%20revista.pdf. Acesso em: 18 de set. 2018.

CAMPOS, Maria Consuelo Campos. Representações da mulher negra na literatura brasileira. In. Anais do XII Seminário Nacional Mulher e Literatura III Seminário Internacional Mulher e Literatura. Ilhéus: UESC, 2007. CD-ROM. Disponível em: http://www.uesc.br/seminariomulher/anais/PDF/Mesas/Maria\%20Consuelo\%20Cunha $\% 20$ Campos.pdf. Acesso em: 05 de març. 2019.

CORREIA, Janaína Santos. Maria Firmina dos Reis: uma contribuição para a escrita da história das mulheres e dos afrodescendentes do Brasil. In. Feminismos, Salvador, v.1, n.3, set./dez. 2013. Disponível em: www.feminismos.neim.ufba.br/index.php/revista/article/download/27/7. Acesso em: 22 fev. 2019 .

COSSON, Rildo. Letramento Literário: teoria e prática. São Paulo: Contexto, 2006. 
DALCASTAGNÈ, Regina. A personagem do romance brasileiro contemporâneo: 1990-2004. In. Estudos de Literatura Brasileira Contemporânea, n. ${ }^{\circ}$ 26. Brasília, julho-dezembro de 2005, p. 13-71.

DALCASTAGNÈ, Regina. Um território contestado: literatura brasileira contemporânea e as novas vozes sociais. Iberic@l: Revue d'études ibériques et ibéro-américaines, Paris, n. 2, 2012, p. 13-18. Disponivel em: http://iberical.paris-sorbonne.fr/wpcontent/uploads/2012/03/lberical-Numero-2.pdf. Acesso em: 05 fev. 2017.

EVARISTO, Conceição. Gênero e etnia: uma escrevivência em dupla face. In: MOREIRA, Nadilza Martins de Barros; SCHNEIDER, Liane (Orgs). Mulheres no Mundo - etnia, marginalidade e diáspora. João Pessoa, PB: Idéia/Editora Universitária, 2005.

FILIPOUSKI, Ana Mariza R.; MARCHI, Diana Maria. A formação do jovem leitor: temas e gêneros da literatura. Erechim, RS: Edelbra, 2009.

MOTTA- ROTH, Desirée. Redação acadêmica: princípios básicos. Santa Maria, RS: UFSM/ Imprensa Universitária, 2001.

NAVARRO, Márcia Hoppe; SCHMIDT, Rita Terezinha. A questão de gênero: ideologia e exclusão. In: $2^{\circ}$ Congresso sobre a 98 | Literatura, espaço autobiográfico e memória Mulher, Gênero e Relações de Trabalho, 2007. Goiânia: Instituto Goiano do Trabalho, 2007. v. 1.

SIMÕES, Luciene J. Leitura e autoria: planejamento em Língua Portuguesa e Literatura. Erechim, RS: Edelbra, 2012.

REIS. Maria F. Úrsula e outras obras. Brasília, DF: Câmara dos Deputados, 2018.

SCHMIDT, Rita T. Repensando a cultura, a literatura e o espaço da autoria feminina. In: NAVARRO, Márcia Hoppe (Org.). Rompendo o silêncio: Gênero e literatura na América Latina. Porto Alegre, RS: Editora Universidade/UFRGS, 1995, p. 182-189.

SCHMIDT, Rita T. Q uem reivindica a identidade? In. Revista Desenredo, Passo Fundo, v. 4, n. 1, p.49-60, jan./jun. 2008.

WATT, Ian. A ascensão do romance: estudos sobre Defoe, Richardson e Fielding. São Paulo: Companhia das Letras, 1990.

Data de submissão: 26/09/2019. Data de aprovação: 17/10/2019. 